Value : Jurnal Manajemen dan Akuntansi

p-ISSN : 1979-0643

Volume 16 Nomor 1

e-ISSN : 2685-7324

\title{
PENGARUH SOCIAL MEDIA MARKETING TERHADAP LOYALITAS KONSUMEN E- COMMERCE MELALUI BRAND IMAGE DAN RELATIONSHIP MARKETING
}

\author{
Danny Khairul ${ }^{1}$ \\ ${ }^{1}$ Sekolah Bisnis, Institut Pertanian Bogor \\ Email: Dannykhairul05@gmail.com
}

\begin{abstract}
The purpose of this paper is to empirically investigate the influence of social media marketing towards brand image and relationship marketing in the Indonesian e-commerce context. The proposed model also aims to examine the relationship between social media marketing, brand image, satisfaction, trust and loyalty. The e-commerce industry in Indonesia is experiencing very tough competition with many emerging platforms. E-commerce industry players must be able to implement strategies to increase consumer loyalty, in order to compete in this industry. The strategy that can be done is by doing social media marketing activities. This is because the Indonesian people are very active in using the internet and social media, so this phenomenon opens up opportunities for business people, especially in the e-commerce industry. Objects in this study addressed to e-commerce consumer in Indonesia. A total of 200 respondents have been obtained throught the distribution of questionnaires by using the method of non-probability sampling. The study model was estimated by using structural equation modelling with LISREL 8.8. The results showed that social media marketing has a significant effect on brand image and trust. Satisfaction and trust have a significant effect on loyalty. Furthermore, brand image has a significant effect on satisfaction, and satisfaction has a significant effect on trust. By contrast, social media marketing has no significant effect on satisfaction, and brand image has no significant effect on loyalty. This study concluded that to increase consumer loyalty in e-commerce, industry players must be able to improve the accuracy of product description suitability, increase responsiveness to complaints and input given by consumers, and increase marketing activities through social media.
\end{abstract}

Keywords: brand image, e-commerce, loyalty, relationship marketing, social media marketing

\section{PENDAHULUAN}

Perkembangan internet di Indonesia saat ini mengalami peningkatan yang cukup signifikan. Pertumbuhan pengguna internet cenderung meningkat secara konsisten dalam kurun waktu yang cukup panjang. Penetrasi pengguna internet di Indonesia pada tahun 2019 sebesar 171.17 juta jiwa atau 64.8\% dari total penduduk. Pertumbuhan pengguna internet yang terus mengalami peningkatan berdampak pada meningkatnya penggunaan media sosial (APJII, 2019). Pada tahun 2020, pengguna aktif media sosial di Indonesia mencapai 160 juta pengguna atau sebesar $62 \%$ dari total populasi. Media sosial yang paling sering digunakan oleh masyarakat yaitu Instagram 50.7\%, Facebook 17.8\%, Twitter $16.4 \%$, dan Youtube $15.1 \%$ (Simon, 2019). Sejalan dengan penetrasi internet, hal ini berdampak pada kemajuan bisnis $e$ commerce. Hal ini dikarenakan platform e-commerce hanya dapat digunakan ketika pengguna terhubung dengan koneksi internet. Pada tahun 2019, Indonesia menjadi Negara dengan tingkat adopsi e-commerce tertinggi di dunia. Perkembangan e-commerce di Indonesia cenderung memiliki tren yang meningkat. Jumlah pengguna e-commerce pada tahun 2020 yakni sebesar 176.5 juta pengguna meningkat sebesar 20.2\% dibanding tahun 2019 dengan jumlah sebesar 147.1 juta pengguna (Statista, 2020). Penetrasi pengguna internet dan media sosial di Indonesia dapat dijadikan sebagai alternatif kegiatan pemasaran yakni melalui social media marketing. Pada praktiknya, pemanfaatan media sosial tidak hanya sebagai sarana berkomunikasi dan hiburan semata, melainkan memiliki posisi penting dalam dunia bisnis sebagai alat pendukung komunikasi pemasaran (Rugova dan Prenai, 2016). Pemanfaatan media sosial sebagai alat pendukung bisnis dapat dilakukan dengan social media marketing sebagai teknik pemasaran untuk mempromosikan produk dan berkolaborasi dengan konsumen untuk mencapai tujuan bisnis. Social media 
marketing tidak hanya sebagai strategi penjualan produk, namun dapat membangun koneksi antara perusahaan dengan pelanggan, bahkan antar pelanggan (Zahay, 2015). Social media marketing dapat meningkatkan efektivitas kegiatan pemasaran dengan jangkauan yang luas serta dapat membangun hubungan jangka panjang dengan pelanggan (Poturak dan Softic 2019).

Penelitian Javed \& Min (2019) mengungkapkan bahwa peningkatan penjualan dapat terjadi jika konsumen merasa puas terhadap produk atau layanan yang diberikan oleh perusahaan. Semakin tinggi tingkat kepuasan konsumen, maka akan berdampak baik pada loyalitas pelanggan dalam mengkonsumsi sebuah brand. Menurut Bilgin (2018) strategi yang digunakan untuk mendapatkan konsumen yang loyal adalah relationship marketing yang mencakup segmentasi dan program loyalitas. Perusahaan akan lebih diuntungkan jika memiliki konsumen yang loyal karena dapat memberikan efisiensi biaya pemasaran perusahaan. Namun untuk mendapatkan konsumen yang loyal, perusahaan perlu membangun hubungan jangka panjang dengan konsumen agar mendapatkan keunggulan kompetitif.

Iprice.com merupakan platform yang memberikan peringkat berdasarkan banyaknya jumlah pengunjung situs e-commerce di Indonesia. Data hasil perangkingan dalam kurun waktu tahun 2017 hingga tahun 2020 menunjukkan bahwa peringkat mengalami perubahan antar situs e-commerce. Pergerakan peringkat menujukkan bahwa konsumen dapat berpindah transaksi dari situs $e$-commerce yang satu ke yang lain dengan mudah. Selain itu, pada tahun 2018 hingga tahun 2020 terdapat tiga kompetitor utama yang selalu bersaing ketat pada industri e-commerce, yakni Tokopedia, Bukalapak, dan Shopee.

Tabel 1 Sepuluh peringkat teratas web traffic tahun 2017-2020

\begin{tabular}{lllll}
\hline No. & 2017 & 2018 & 2019 & 2020 \\
\hline 1. & Lazada & Tokopedia & Tokopedia & Shopee \\
2. & Tokopedia & Bukalapak & Shopee & Tokopedia \\
3. & Bukalapak & Shopee & Bukalapak & Bukalapak \\
4. & Blibli & Lazada & Lazada & Lazada \\
5. & Shopee & Blibli & Blibli & Blibli \\
6. & JD.id & JD.id & JD.id & JD.id \\
7. & Blanja.com & Zalora & Bhinneka & Orami \\
8. & Zalora & Sale Stock Indonesia & Sociolla & Bhinneka \\
9. & Elevania & Elevania & Orami & Zalora \\
10. & Bhinneka & iLotte & Ralali & Matahari \\
\hline
\end{tabular}

Sumber: Iprice.com (data diolah)

Berdasarkan riset Iprice (2019), jumlah pengunjung pada ketiga kompetitor utama industri $e$ commerce pada masing-masing kuartal tahun 2019 mengalami persaingan ketat (Gambar 1). Masingmasing kompetitor berusaha untuk menjadi yang terdepan dalam industri e-commerce.

Gambar 1 Jumlah pengunjung e-commerce di Indonesia tahun 2019

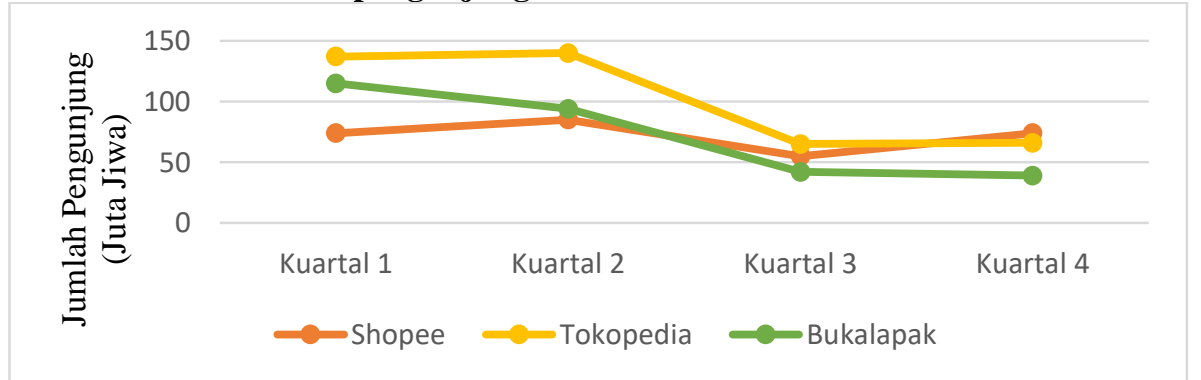

Sumber: Iprice (2019)

Gambar 1 menunjukkan bahwa terjadi fluktuasi jumlah pengunjung e-commerce di sepanjang kuartal tahun 2019. Oleh karena itu, strategi peningkatan jumlah pengunjung dan loyalitas pelanggan perlu dikaji oleh perusahaan yang bergerak pada industri ini. Selain itu, tulisan ini mencoba mengisi kesenjangan penelitian sebelumnya: social media marketing untuk mengevaluasi efektivitas kegiatan pemasaran oleh Zhang et al. (2016), brand image industri e-commerce seperti yang diteliti oleh Seo \& Park (2018), relationship marketing konsumen belanja online oleh Aldweeri et al. (2018), dan hubungan dengan loyalitas 
konsumen e-commerce seperti yang diteliti oleh Wang et al. (2015). Penelitian ini dilakukan pada konsumen e-commerce $\mathrm{C} 2 \mathrm{C}$ (consumer-to-consumer) sebagai salah satu industri belanja online yang berkembang pesat di Indonesia.

\section{KAJIAN PUSTAKA DAN PENGEMBANGAN HIPOTESIS Social Media Marketing}

Social media marketing didefinisikan sebagai pemanfaatan teknologi media sosial untuk berkomunikasi, menyampaikan dan bertukar penawaran yang memiliki nilai bagi pemangku kepentingan organisasi (Tuten, 2008). Social media marketing merupakan pemanfaatan media sosial dalam memasarkan produk dan layanan melalui tools media sosial seperti blog, facebook, twitter, instagram, youtube, dll (Alfian \& Nilowardono, 2019).

Media sosial dianggap sebagai bagian dari integrated marketing communication dengan menyediakan platform yang memungkinkan adanya interaksi antar sesama pengguna. Media sosial dapat menjadi strategi efektif untuk menjangkau dan melibatkan konsumen potensial, serta mendorong adanya interaksi antara perusahaan dengan konsumen, dan antar konsumen itu sendiri (Tatar \& Erdogmus, 2016). Penelitian Aldweeri et al. (2018) menunjukkan bahwa popularitas media sosial saat ini dapat menjadi strategi bisnis. Hal ini dikarenakan tingginya intensitas penggunaan media sosial, dan efisiensi biaya pemasaran. Dalam konteks e-commerce, Social media marketing didefinisikan sebagai proses yang dilakukan oleh perusahaan dalam berkomunikasi dan melakukan kegiatan pemasaran online melalui platform media sosial untuk membangun dan memelihara hubungan pemangku kepentingan dengan kegiatan interaksi, berbagi informasi, dan merekomendasikan pembelian (Ismail, 2017). Menurut Yadav \& Rahman (2017) terdapat empat dimensi social media marketing yaitu: interactivity, personalization, informativeness, dan word-of-mouth (WOM).

Intercativity mengacu pada persepsi pelanggan tentang sejauh mana media sosial e-commerce memfasilitasi pelanggan untuk berbagi konten dan pandangan dengan perusahaan dan pelanggan lain (Seo \& Park, 2018). Kedua yaitu personalization mengacu pada persepsi pelanggan tentang sejauh mana media sosial e-commerce menawarkan konten serta layanan yang sesuai dengan preferensi pelanggan (Bilgin, 2018). Ketiga yaitu informativeness merupakan persepsi pelanggan tentang sejauh mana media sosial $e$ commerce menawarkan informasi yang akurat, berguna, dan komprehensif (Cheung et al., 2020). Terakhir adalah word-of-mouth yang mengacu pada persepsi pelanggan untuk merekomendasikan dan berbagi pengalaman terhadap produk dan layanan yang dikonsumsi melalui media sosial (Yadav \& Rahman, 2017).

\section{Brand Image}

Menurut Lee et al. (2011) menyatakan bahwa brand image sebagai persepsi konsumen dan preferensi untuk suatu merek. Citra merek mengandung informasi dan gagasan tentang berbagai fitur produk. Brand image terbentuk sebagai hasil dari komunikasi pemasaran, pengalaman konsumsi, dan pengaruh sosial (Riezebos, 2003), Iversen \& Hem (2008) mendefinisikan brand image sebagai representasi simbolisme konsumen terhadap evaluasi merek. Brand image dapat membantu konsumen dalam mengenali kebutuhan dan kepuasan mereka tentang merek, sekaligus menjadi pembeda antar kompetitor dan memotivasi pelanggan untuk membeli merek tersebut (Hsieh et al., 2004).

Image yang diciptakan oleh perusahaan dapat membantu konsumen dalam mengumpulkan informasi, membedakan merek, dan menciptakan alasan untuk membeli (Upamanyu \& Mathur, 2012). Brand image adalah kumpulan asosiasi merek yang terbentuk dan melekat dibenak konsumen. Brand image merupakan faktor penting dalam pengambilan keputusan oleh konsumen. Brand image yang kuat dapat memperkuat daya saing perusahaan (Severi \& Ling, 2013). Brand image merupakan alat yang ampuh untuk menarik pelanggan baru dengan memengaruhi perilaku mereka menggunakan berbagai strategi yang akan membuat mereka loyal pada suatu merek (Pavlou \& Fygenson, 2006).

\section{Relationship Marketing}

Relationship marketing didefinisikan sebagai aktivitas pemasaran yang diarahkan untuk membangun, mengembangkan, dan memelihara hubungan jangka panjang melalui kolaborasi dengan pelanggan sehingga tujuan semua pihak dapat terpenuhi (Morgan \& Hunt, 1994). Relationship marketing 
merupakan orientasi strategis yang berfokus pada pengembangan loyalitas pelanggan melalui kegiatan kolaboratif dan kooperatif untuk meningkatkan nilai ekonomis. Memelihara hubungan jangka panjang dengan konsumen merupakan syarat penting untuk kesuksesan sebuah organisasi (Hoang, 2015). Penelitian yang dilakukan oleh Jamaev et al. (2012) menyatakan bahwa relationship marketing merupakan elemen penting dalam proses riset pemasaran, sehingga dapat membantu organisasi meningkatkan profitabilitas dan keunggulan kompetitif melalui globalisasi pasar dunia, serta memberikan manfaat jangka panjang bagi konsumen dan perusahaan. Sun (2010) membagi relationship marketing menjadi dua yaitu satisfaction dan trust.

Satisfaction didefinisikan sebagai perasaan senang atau kecewa seseorang yang timbul karena membandingkan produk yang dibeli terhadap ekspektasi mereka. Jika kinerja tidak dapat memenuhi ekspektasi, maka pelanggan akan merasa tidak puas / kecewa. Jika kinerja melebihi ekspektasi, maka pelanggan akan merasa sangat puas atau senang (Kotler \& Keller, 2016). Penilaian pelanggan atas kinerja produk bergantung pada banyak faktor, terutama jenis hubungan loyalitas yang dimiliki pelanggan dengan sebuah merek. Konsumen sering membentuk persepsi yang lebih menyenangkan tentang sebuah produk dengan merek yang sudah mereka anggap positif (Mothersbaugh \& Hawkins, 2016).

Kepercayaan dipandang sebagai salah satu anteseden paling relevan dalam hubungan yang stabil dan kolaboratif (Akbar \& Pavej, 2009). Konsep kepercayaan adalah salah satu elemen paling penting yang mengarah pada terciptanya hubungan jangka panjang dengan pelanggan, terutama dalam menjaga kerahasiaan informasi pelanggan, dan komitmen untuk memberikan layanan terbaik (Ball et al., 2004). Kepercayaan konsumen didefinisikan sebagai harapan konsumen bahwa penyedia jasa dapat diandalkan dalam memenuhi janjinya (Baig et al., 2015). Pada industri belanja online, kepercayaan didefinisikan sebagai keyakinan pembeli bahwa penjual online berprilaku etis (Pavlou \& Fygenson, 2006). Kepercayaan dan kepuasan menjadi faktor penting untuk mendapatkan retensi pelanggan ketika menghadapi situasi negatif seperti kegagalan dalam layanan dan memainkan peran penting terhadap loyalitas (Liao \& Keng, 2013).

\section{Loyalty}

Loyalitas merupakan komitmen pelanggan untuk mengulangi pembelian secara teratur (Peelen, 2005). Loyalitas pelanggan didefinisikan sebagai kesediaan pelanggan dalam menggunakan dan membeli produk atau layanan pada salah satu perusahaan secara berulang, tidak mudah terpengaruh oleh merek lain, serta sukarela memperkenalkan produk dan layanan tersebut kepada orang lain (Hoang, 2015). Loyalitas merupakan suatu komitmen yang dimiliki untuk membeli dan menggunakan produk atau layanan yang sama. Pelanggan yang berulang kali pergi ke tempat yang sama untuk memuaskan keinginan dengan mendapatkan dan membayar produk atau layanan (Kotler \& Keller, 2016).

Olivier (1999) mendefinisikan loyalitas pelanggan sebagai komitmen yang dipegang teguh oleh pelanggan untuk membeli kembali produk atau layanan secara terus menerus dimasa mendatang. Jika organisasi ingin memiliki banyak pelanggan setia, maka mereka perlu memberikan manfaat sosial dan finansial kepada pelanggan mereka. Loyalitas dapat dibangun dengan menjalin hubungan jangka panjang, memberikan insentif, mengelola keluhan pelanggan, dan mendorong adanya feedback dari pelanggan (Ismail, 2017). Strategi peningkatan loyalitas pelanggan dapat memelihara hubungan jangka panjang, mengurangi biaya pemasaran, dan memperkaya penjualan (Khan et al., 2016).

\section{Social Media Marketing, Brand Image, Relationship Marketing dan Loyalty}

Penelitian Anizir \& Wahyuni (2017) menunjukkan bahwa social media marketing memiliki pengaruh signifikan terhadap brand image. Penelitian serupa dilakukan oleh Bilgin (2018) menunjukkan bahwa brand image menjadi faktor penting ditengah pasar yang kompetitif. Dengan peningkatan pengguna media sosial, maka platform ini dapat dimanfaatkan untuk strategi pemasaran yang efektif. Didukung oleh Duffett (2017) yang mengungkapkan bahwa aktivitas pemasaran melalui media sosial dapat meningkatkan brand image. Social media marketing dapat meningkatkan citra dan memperkuat komunikasi word of mouth. Berdasarkan pemaparan penelitian terdahulu tersebut, hipotesis yang ingin diuji adalah:

\section{H1: Social media marketing berpengaruh signifikan terhadap brand image konsumen e-commerce}


Fajri \& Maruf (2018) mengungkapkan bahwa social media marketing memiliki pengaruh signifikan terhadap satisfaction. Implementasi program pemasaran melalui media sosial terbukti efektif untuk menciptakan hubungan yang menguntungkan dengan konsumen. Hal ini didukung oleh penelitian Pratama (2016) bahwa social media marketing melibatkan konsumen untuk berinteraksi serta berkolaborasi dengan perusahaan. Hal ini dapat membangun kedekatan dan memelihara hubungan dengan konsumen. Keterlibatan konsumen akan berdampak baik bagi perusahaan. Zaryab et al. (2019) melakukan penelitian untuk menganalisis pengaruh social media marketing terhadap satisfaction pada industri e-commerce. Hasil dari penelitian tersebut mengungkapkan bahwa social media marketing memiliki pengaruh positif dan signifikan terhadap satisfaction pelanggan e-commerce. Berdasarkan pemaparan penelitian terdahulu tersebut, hipotesis yang ingin diuji adalah:

\section{H2: Social media marketing berpengaruh signifikan terhadap satisfaction konsumen e-commerce}

Gautam \& Sharma (2017) mengungkapkan bahwa social media marketing memiliki pengaruh signifikan terhadap trust. Melalui media sosial, konsumen dapat membagikan pengalaman belanjanya. Lu \& Hsiao (2010) mengungkapkan bahwa cara membangun kepercayaan ialah dengan menyediakan saluran komunikasi khusus bagi konsumen yang ingin menyampaikan keluhan dan saran. Sehingga tercipta kesan bahwa brand tersebut sangat memperhatikan dan ingin memenuhi kebutuhan konsumen yang belum terpenuhi. Didukung oleh Jalilvand et al. (2017) mengungkapkan bahwa terdapat pengaruh positif dan signifikan antara social media marketing dan kepercayaan konsumen. Berdasarkan pemaparan penelitian terdahulu tersebut, hipotesis yang ingin diuji adalah:

\section{H3: Social media marketing berpengaruh signifikan terhadap trust konsumen $e$-commerce}

Andreani et al. (2012) mengungkapkan bahwa brand image dapat meningkatkan kepuasan konsumen. Perusahaan yang memiliki reputasi yang baik, akan berdampak pada meningkatnya kesadaran merek dan kepuasan pelanggan. Subaesbasni et al. (2018) melakukan penelitian tentang pengaruh brand image terhadap customer satisfaction yang berdampak pada customer loyalty. Hasil penelitian mengungkapkan bahwa brand image memiliki pengaruh signifikan terhadap satisfaction. Berdasarkan pemaparan penelitian terdahulu tersebut, hipotesis yang ingin diuji adalah:

\section{H4: Brand image berpengaruh signifikan terhadap satisfaction konsumen e-commerce}

Penelitian Javed dan Min (2019) menyimpulkan bahwa satisfaction berpengaruh positif dan signifikan terhadap trust konsumen online shopping. Menurut Santos (2003), perusahaan berbasis online harus menunjukkan minat yang tulus dalam meningkatkan kepuasan dan kepercayaan pelanggan dalam berbelanja online. Ketika pelanggan merasa puas terhadap layanan yang diberikan, maka hal tersebut dapat meningkatkan kepercayaan pelanggan pada barang yang mereka konsumsi. Berdasarkan pemaparan penelitian terdahulu tersebut, hipotesis yang ingin diuji adalah:

\section{H5: Satisfaction berpengaruh signifikan terhadap trust konsumen $e$-commerce}

Saeed et al. (2013) melakukan penelitian tentang pengaruh brand image terhadap customer loyalty melalui kepuasan pelanggan. Hasil penelitian menunjukkan bahwa brand image berpengaruh positif dan signifikan terhadap loyalitas pelanggan. Penelitian serupa dilakukan oleh Sublibhavi dan Shivashankar (2017) yang mengungkapkan bahwa semakin baik strategi perusahaan dalam meningkatkan brand image maka berdampak pada peningkatan loyalitas pelanggan. Berdasarkan pemaparan penelitian terdahulu tersebut, hipotesis yang ingin diuji adalah:

\section{H6: Brand image berpengaruh signifikan terhadap loyalitas konsumen e-commerce}

Ngo \& Pavelkova (2017) melakukan penelitian tentang pengaruh kepuasan terhadap loyalitas pelanggan. Hasil penelitian mengungkapkan bahwa kepuasan pelanggan dapat menyebabkan loyalitas. Hal ini dikarenakan konsumen cenderung untuk mengurangi resiko untuk mencoba merek baru, sehingga konsumen tersebut lebih memilih untuk tetap mengkonsumsi produk dan layanan yang memberikan pengalaman sesuai dengan ekpekstasi konsumen. Hasil penelitian ini menunjukkan bahwa kepuasan menjadi kunci utama dan titik awal dari loyalitas. Berdasarkan pemaparan penelitian terdahulu tersebut, hipotesis yang ingin diuji adalah:

H7: Satisfaction berpengaruh signifikan terhadap loyalitas konsumen e-commerce 
Konsep kepercayaan adalah salah satu elemen paling penting yang mengarah pada terciptanya hubungan jangka panjang dengan pelanggan, terutama dalam menjaga kerahasiaan informasi pelanggan, dan komitmen untuk memberikan layanan terbaik (Singh \& Sirdeshmukh, 2000). Penelitian Hoang (2015) mengungkapkan bahwa trust memiliki pengaruh signifikan terhadap loyalitas. Kepercayaan dapat meningkatkan loyalitas konsumen, terutama dalam belanja online. Berdasarkan pemaparan penelitian terdahulu tersebut, hipotesis yang ingin diuji adalah:

\section{H8: Trust berpengaruh signifikan terhadap loyalitas konsumen $e$-commerce}

\section{Gambar 2. Kerangka Konseptual}

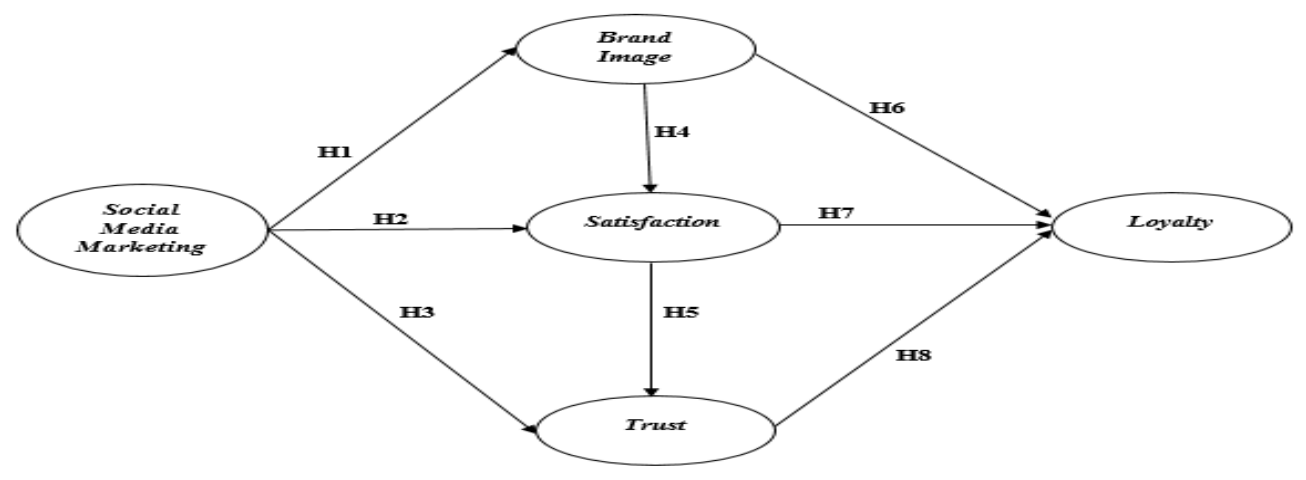

\section{METODE PENELITIAN}

Pengambilan data responden dilakukan di Indonesia. Adapun penelitian ini berlangsung selama periode bulan Juni 2020 - Desember 2020. Pendekatan yang digunakan dalam penelitian ini menggunakan metode kuantitatif melalui survei. Syarat sampel yang ditetapkan adalah konsumen yang pernah melakukan transaksi pada situs e-commerce minimal dua kali dalam 3 bulan terakhir dan merupakan pengguna aktif Instagram. Penelitian ini menggunakan jumlah sampel sebanyak 200 responden. Menurut Hair et al. (2006) jumlah sampel yang dibutuhkan untuk setiap estimasi parameter variabel eksogen dan endogen adalah lima hingga sepuluh observasi. Teknik pengambilan sampel pada penelitian ini menggunakan non-probability sampling dengan pendekatan voluntary.

Penelitian ini menggunakan kuesioner online melalui Google Docs. Kuesioner yang diberikan berisikan pertanyaan terstruktur yang dibatasi oleh pertanyaan screening, profiling dan pertanyaan terkait dengan variabel penelitian yang memengaruhi loyalitas konsumen e-commerce. Penyebaran kuesioner dilakukan dengan cara posting pada grup media sosial dan direct message kepada responden yang sesuai dengan syarat penelitian. Sumber data yang digunakan terdiri dari data primer dan sekunder. Data primer diperoleh dari hasil pernyataan responden melalui penyebaran kuesioner. Kuesioner yang diberikan kepada responden berisikan jenis pertanyaan terstruktur yang dibuat sedemikian rupa sehingga responden dibatasi dalam ruang pemberian jawaban. Jawaban pertanyaan terstruktur responden menggunakan skala Likert (Summated Rating Scale). Data sekunder dalam penelitian diperoleh dari berbagai sumber literatur, yakni buku, jurnal, dan artikel.

Analisis deskriptif adalah statistik yang digunakan untuk menganalisa data dengan cara mendeskripsikan atau menggambarkan data yang telah terkumpul sebagaimana adanya tanpa bermaksud membuat kesimpulan yang berlaku untuk digeneralisasikan (Sekaran \& Bougie, 2013). Dalam penelitian ini analisis deskriptif digunakan untuk mengetahui gambaran karakteristik responden dan perilaku konsumsi responden. SEM merupakan model statistik yang digunakan untuk menguji hubungan kausalitas antar konstruk serta mengukur kelayakan model dan mengkonfirmasinya sesuai dengan data impiris. Keunggulan teknik analisis ini adalah dapat menentukan hubungan antara measurable variabel (manifest) dengan konstruk atau variabel laten, seperti dalam analisis faktor, dan menentukan koefisien pengaruh konstruk yang satu dengan konstruk lainnya (Ghozali \& Latan, 2015). Pembentukan model SEM berdasarkan kerangka pemikiran konseptual pada penelitian ini akan diolah dengan menggunakan software LISREL 8.8. 


\section{HASIL PENELITIAN Profil responden}

Responden pada penelitian ini didominasi oleh perempuan dengan jumlah sebesar 58 persen dengan mayoritas responden berusia antara 20-30 tahun diikuti usia 31-40 tahun sebesar 24.5 persen dan usia 41-50 tahun sebesar 5.5 persen. Mayoritas responden berasal dari pulau Jawa diikuti oleh pulau Sumatera sebesar 21 persen pulau Bali sebesar 9 persen pulau Sulawesi sebesar 5.5 persen dan pulau Kalimantan sebesar 3.5 persen. Sebanyak 33.5 persen responden merupakan mahasiswa diikuti oleh kategori pegawai swasta sebanyak 29 persen. Sebesar 19 persen merupakan kategori wirausaha diikuti oleh pegawai BUMN sebesar 14.5 persen dan PNS/TNI/POLRI sebesar 2.5 persen. Responden dengan kategori ibu rumah tangga menempati urutan terakhir yaitu 1.5 persen. Responden dengan latar pendidikan S1 mendominasi dengan jumlah sebesar 67.5 persen diikuti latar belakang pendidikan SMA/SMK sebanyak 19 persen. Responden dengan latar belakang pendidikan Diploma sebanyak 7 persen dan sisanya sebanyak 6.5 persen berlatar belakang pendidikan S2/S3. Mayoritas responden berpenghasilan 5 hingga 10 juta rupiah per bulan dengan persentase sebesar 39 persen diikuti dengan kategori penghasilan kurang dari 5 juta rupiah sebesar 36 persen dan kategori penghasilan lebih dari 10 juta rupiah sebesar 25 persen.

\section{Evaluasi Tingkat Kecocokan Model}

Pengaruh social media marketing terhadap loyalitas konsumen e-commerce melalui brand image dan relationship marketing diukur menggunakan model SEM. Menurut Hair et al. (2006) evaluasi kecocokan dilakukan melalui beberapa tahap, yaitu 1) kecocokan keseluruhan model; 2) kecocokan model pengukuran; 3) kecocokan model struktural.

\section{Uji Kecocokan Keseluruhan Model}

Menurut Wijayanto (2008) analisis SEM tidak mempunyai uji statistik terbaik yang dapat menjelaskan kekuatan prediksi model. Sebagai gantinya para peneliti telah mengembangkan beberapa ukuran kriteria goodness of fit yang dapat digunakan secara bersama-sama atau kombinasi. Ghozali \& Latan (2015) menyatakan bahwa dalam suatu penelitian empiris, seorang peneliti tidak dituntut untuk memenuhi semua kriteria goodness of fit, akan tetapi tergantung dari judgemental masing-masing peneliti. Menurut Hair et al. (2006) penggunaan 4-5 kriteria goodness of fit dianggap sudah mencukupi untuk menilai kelayakan suatu model. Uji kecocokan model dapat dilihat dari kriteria RMSEA, GFI, AGFI, NFI, IFI, dan CFI yang dapat dilihat pada Tabel 2. Nilai keseluruhan aspek kriteria kesesuain tersebut telah termasuk kategori good fit dan marginal fit sehingga secara keseluruhan model penelitian ini dinyatakan layak.

Tabel 2. Hasil uji kecocokan keseluruhan model

\begin{tabular}{lcll}
\hline \multicolumn{1}{c}{ Goodness of Fit } & Cut off value & Hasil & Keterangan \\
\hline Root Mean Square Error of Approximation (RMSEA) & $\leq 0.08$ & 0.073 & Good Fit \\
Goodness of Fit Index (GFI) & $\geq 0.9$ & 0.81 & Marginal Fit \\
Adjusted Goodness of Fit Index (AGFI) & $\geq 0.9$ & 0.84 & Marginal Fit \\
Normed Fit Index (NFI) & $\geq 0.9$ & 0.91 & Good Fit \\
Incremental Fit Index (IFI) & $\geq 0.9$ & 0.94 & Good Fit \\
Comparative Fit Index (CFI) & $\geq 0.9$ & 0.94 & Good Fit \\
\hline
\end{tabular}

\section{Uji Kecocokan Model Pengukuran}

Uji kecocokan model pengukuran dilakukan dengan uji validitas dan reliabilitas. Validitas mengukur sejauh mana suatu indikator secara akurat mengukur apa yang seharusnya diukur (Haryono, 2016). Uji kecocokan model pengukuran dapat dilihat pada Tabel 3.

Atribut dinyatakan valid jika nilai standardize loading factor (SLF) $\geq 0.5$ dan memiliki nilai t-value diatas 1.96 (Hair et al., 2006). Berdasarkan Tabel 3 dapat dilihat bahwa semua indikator pada variabel memenuhi syarat validitas dengan ditnjukkan oleh nilai standardized factor loading lebih besar dari 0.50 dan nilai t-value diatas 1.96 atau termasuk kategori signifikan. 
Value : Jurnal Manajemen dan Akuntansi

p-ISSN : 1979-0643

Volume 16 Nomor 1

e-ISSN : 2685-7324

Tabel 3. Uji kecocokan model pengukuran

\begin{tabular}{|c|c|c|c|c|}
\hline Variabel Laten & Indikator & $\begin{array}{r}\text { Loading } \\
\text { Factor } \\
\end{array}$ & t-hitung & Ket. \\
\hline & Interactivity (IN) & 0.79 & 8.73 & Valid \\
\hline \multirow[t]{16}{*}{ SMM } & IN1 & 0.70 & - & Valid \\
\hline & IN2 & 0.86 & 11.33 & Valid \\
\hline & IN3 & 0.93 & 12.07 & Valid \\
\hline & IN4 & 0.82 & 10.80 & Valid \\
\hline & IN5 & 0.56 & 7.51 & Valid \\
\hline & Informativeness (IF) & 0.77 & 6.96 & Valid \\
\hline & IF1 & 0.55 & - & Valid \\
\hline & IF2 & 0.97 & 8.51 & Valid \\
\hline & IF3 & 0.86 & 8.36 & Valid \\
\hline & Personalization (PR) & 0.90 & 8.13 & Valid \\
\hline & PR1 & 0.71 & - & Valid \\
\hline & PR2 & 0.76 & 7.54 & Valid \\
\hline & Word-of-mouth (WOM) & 0.70 & 9.37 & Valid \\
\hline & WOM1 & 0.91 & - & Valid \\
\hline & WOM2 & 0.92 & 17.68 & Valid \\
\hline & WOM3 & 0.73 & 12.11 & Valid \\
\hline \multirow[t]{4}{*}{ BI } & BI1 & 0.74 & - & Valid \\
\hline & BI2 & 0.69 & 6.13 & Valid \\
\hline & BI3 & 0.78 & 6.71 & Valid \\
\hline & BI4 & 0.76 & 7.12 & Valid \\
\hline \multirow[t]{5}{*}{ CS } & CS1 & 0.73 & - & Valid \\
\hline & $\mathrm{CS} 2$ & 0.77 & 10.64 & Valid \\
\hline & CS3 & 0.74 & 10.15 & Valid \\
\hline & CS4 & 0.84 & 11.71 & Valid \\
\hline & CS5 & 0.80 & 11.04 & Valid \\
\hline \multirow[t]{4}{*}{ TR } & TR1 & 0.72 & - & Valid \\
\hline & TR2 & 0.75 & 9.14 & Valid \\
\hline & TR3 & 0.58 & 7.30 & Valid \\
\hline & TR4 & 0.62 & 7.83 & Valid \\
\hline \multirow[t]{4}{*}{ LY } & LY1 & 0.82 & - & Valid \\
\hline & LY2 & 0.71 & 10.22 & Valid \\
\hline & LY3 & 0.80 & 11.78 & Valid \\
\hline & LY4 & 0.60 & 8.44 & Valid \\
\hline
\end{tabular}

Keterangan: jika nilai standardized loading factor (SLF) $\geq 0.5$ dan t-hitung $>1.96$ maka indikator pada variabel memiliki validitas yang baik

Reliabilitas merupakan ukuran mengenai konsistensi internal dari sebuah indikator-indikator sebuah konstruk. Hasil reliabilitas yang tinggi memberikan keyakinan bahwa masing-masing indikator konsisten dengan pengukurannya. Hasil pengukuran uji reliabilitas menunjukkan tidak semua nilai Construct Reliability (CR) dan Variance Extracted (VE) memenuhi syarat reliabilitas, yakni nilai CR $\geq 0.7$ dan nilai $\mathrm{VE} \geq 0.5$. Nilai VE untuk setiap variabel laten yang memiliki nilai $>0.5$ sangat direkomendasikan. Tabel 4 menjelaskan tentang nilai Construct Reliability (CR) dan Variance Extracted (VE).

Berdasarkan Tabel 4 diperoleh bahwa social media marketing, interactivity, informativeness, personalization, word-of-mouth, brand image, satisfaction, dan loyalitas memenuhi syarat reliabel dengan nilai $C R \geq 0.7$ dan nilai $\mathrm{VE} \geq 0.5$. Artinya seluruh variabel maupun indikator tersebut mewakili secara baik konstruk laten yang dikembangkan. Hal ini mengindikasikan bahwa setiap variabel indikator valid untuk mengukur konstruk latennya. Berdasarkan Tabel 4, nilai VE pada trust menunjukkan kurang dari 0.5, namun masih memiliki nilai Construct Reliability (CR) lebih dari 0.7 maka convergent validity dari konstruk laten tersebut masih dapat dikatakan cukup memadai. 
Tabel 4. Nilai contruct reliability (CR) dan variance extracted (VE)

\begin{tabular}{lllll}
\hline & Variabel Laten & Variabel Indikator & CR & VE \\
\hline 1. & Social media marketing & IN - WOM & 0.95 & 0.63 \\
& Interactivity $($ IN) & IN1 - IN5 & 0.88 & 0.61 \\
& Informativeness (IF) & IF1 - IF3 & 0.84 & 0.66 \\
& Word-of-mouth (WOM) & WOM1 - WOM3 & 0.89 & 0.73 \\
2. & Brand image & BI1 - BI4 & 0.83 & 0.55 \\
3. & Satisfaction & CS1 - CS5 & 0.88 & 0.60 \\
4. & Trust & TR1 - TR4 & 0.76 & 0.45 \\
$\mathbf{5 .}$ & Loyalty & LY1 - LY4 & 0.82 & 0.54 \\
\hline
\end{tabular}

Suatu variabel dikatakan cukup konsisten apabila variabel tersebut memiliki Construct Reliability $(\mathrm{CR})>0.7$. Tabel 4 menunjukkan bahwa semua nilai CR > 0.7. Oleh karena itu dapat disimpulkan bahwa indikator-indikator yang digunakan pada penelitian ini memiliki reliabilitas yang baik atau mampu untuk mengukur konstruknya. Hasil evaluasi model pengukuran menunjukkan bahwa model secara keseluruhan fit dengan data, sehingga hasil penelitian ini dapat dinyatakan valid dan reliabel.

\section{Uji Kecocokan Model Struktural}

Uji kecocokan model struktural dilakukan setelah secara keseluruhan model dianalisis kesesuaiannya. Hasil uji kecocokan model disajikan pada Gambar 3. Pendekatan yang digunakan untuk menguji kecocokan model struktural adalah dengan menentukan t-hitung dari setiap variabel laten harus lebih besar dari 1,96 agar hipotesis dapat diterima pada taraf signifikansi 0.05 (tingkat kepercayaan 95\%).

\section{Gambar 3. Model pengukuran SEM}

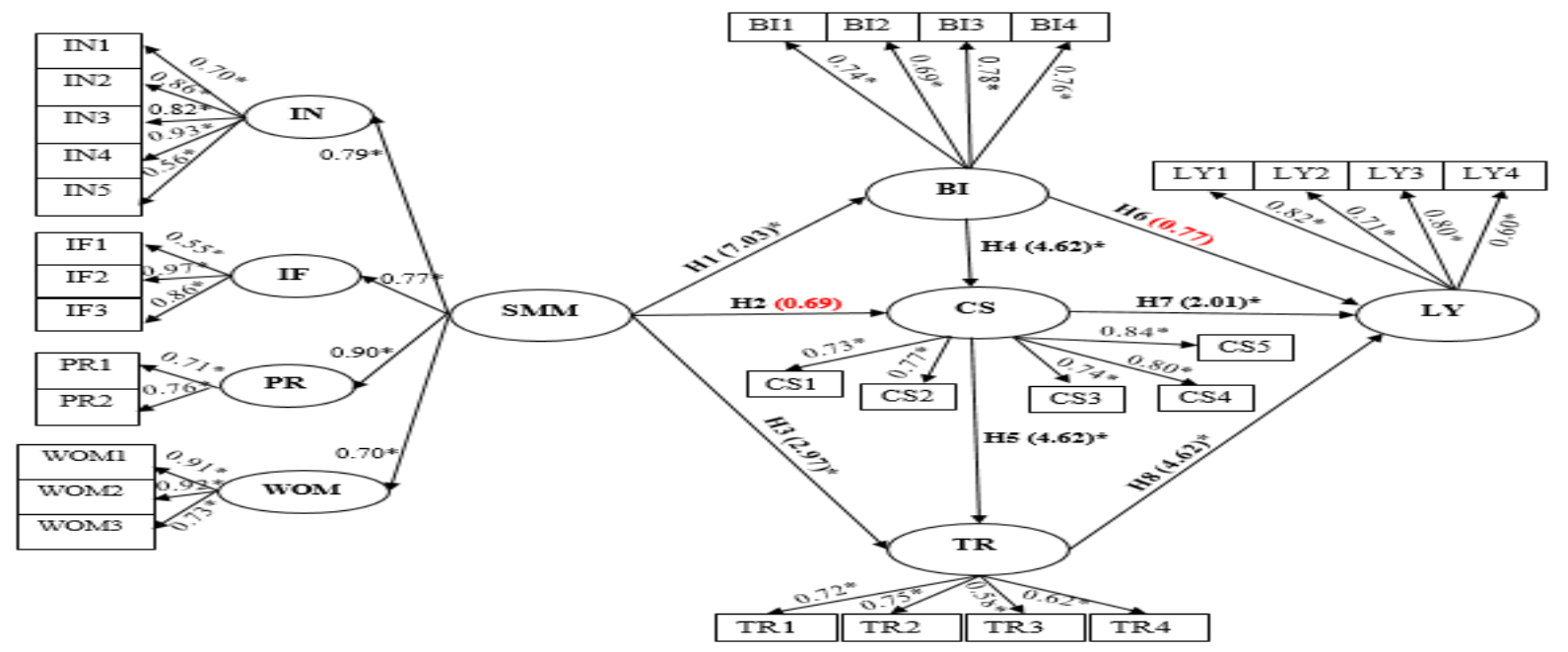

\section{PEMBAHASAN}

Penelitian ini bertujuan untuk menganalisis pengaruh social media marketing, brand image, satisfaction, trust dan loyalty satu sama lain. Gambar 3 dan Tabel 5 menunjukkan hasil uji pengaruh antar variabel.

Tabel 5. Hasil uji hipotesis

\begin{tabular}{llcclll}
\hline \multicolumn{3}{c}{ Pengaruh variabel } & Koefisien jalur & t-hitung & \multicolumn{1}{c}{ Simpulan } & Keterangan \\
\hline Social media marketing & $\rightarrow$ & Brand image & 0.75 & 7.03 & Signifikan & Terima H1 \\
Social media marketing & $\rightarrow$ & Satisfaction & 0.09 & 0.69 & Tidak Signifikan & Tolak H2 \\
Social media marketing & $\rightarrow$ & Trust & 0.25 & 2.97 & Signifikan & Terima H3 \\
Brand image & $\rightarrow$ & Satisfaction & 0.85 & 4.62 & Signifikan & Terima H4 \\
Satisfaction & $\rightarrow$ & Trust & 0.54 & 5.53 & Signifikan & Terima H5 \\
Brand image & $\rightarrow$ & Loyalty & 0.10 & 0.77 & Tidak Signifikan & Tolak H6 \\
Satisfaction & $\rightarrow$ & Loyalty & 0.26 & 2.01 & Signifikan & Terima H7 \\
Trust & $\rightarrow$ & Loyalty & 0.52 & 4.62 & Signifikan & Terima H8 \\
\hline
\end{tabular}


Social media marketing memiliki pengaruh signifikan terhadap brand image (H1). Hal ini sesuai dengan studi terdahulu yang dilakukan oleh Hermanda et al. (2019) mengenai industri belanja online. Hipotesis ke-1 memiliki arti bahwa social media marketing memiliki pengaruh terhadap peningkatan brand image industri e-commerce. Berdasarkan hasil SEM, responden merasa pemanfaatan salah satu fitur social media marketing yaitu dapat berdiskusi/bertukar pendapat dari pengguna instagram terhadap kualitas jasa dari e-commerce merupakan hal yang paling diperhitungkan dalam social media marketing. Yadav \& Rahman (2017) mengatakan bahwa diskusi/pertukaran pendapat secara online dapat mengurangi ketidakpastian terhadap produk sehingga konsumen lebih percaya terhadap suatu produk. Anizir \& Wahyuni (2017) mengungkapkan bahwa konsumen merasa diskusi/pertukaran pendapat yang dilakukan oleh pengguna instagram dapat menjadi pembanding terhadap iklan produk/jasa yang ditawarkan perusahaan.

Selanjutnya, social media marketing tidak memiliki pengaruh yang signifikan terhadap satisfaction (H2). Hasil ini berbeda dengan penelitian terdahulu yang dilakukan oleh Fajri \& Maruf (2018) mengenai pengaruh social media marketing di industri e-commerce. Hal ini diduga bahwa konsumen e-commerce akan merasa puas jika mereka telah mengkonsumsi produk/jasa tersebut. Kepuasan konsumen tidak langsung terjadi ketika mereka melihat iklan situs e-commerce di media sosial.

Berikutnya, terdapat pengaruh yang signifikan antara social media marketing dengan trust (H3). Hasil tersebut sejalan dengan studi terdahulu yang dilakukan oleh Jakic et al. (2017) yang menyatakan bahwa kegiatan social media marketing dapat meningkatkan kepercayaan konsumen e-commerce. Responden merasa pemanfaatan salah satu fitur social media marketing yaitu dapat berdiskusi/bertukar pendapat dari pengguna instagram terhadap e-commerce merupakan hal yang diperhitungkan dalam social media marketing. Amalina (2016) mengungkapkan bahwa salah satu cara untuk membangun kepercayaan konsumen adalah dengan menyediakan saluran khusus bagi konsumen yang ingin berdiskusi/bertukar pendapat serta menyampaikan keluhan dan saran. Dengan mengelola media sosial secara profesional, akan menimbulkan kepercayaan pada merek yang dikelola oleh media sosial tersebut.

Selanjutnya, pada penelitian ini brand image memiliki pengaruh yang signifikan terhadap satisfaction (H4). Hasil tersebut sejalan dengan penelitian terdahulu yang dilakukan oleh Subaesbasni et al. (2018) yang menyatakan bahwa brand image dapat meningkatkan kepuasan konsumen. Indikator brand image yang berkontribusi paling kuat adalah situs e-commerce merupakan leader di industri belanja online. Keberhasilan merek dapat membangkitkan kesadaran dan kepuasan konsumen. Dalam hal ini, brand image dapat dipengaruhi oleh banyak faktor seperti intensitas iklan, kesan positif, dan kesesuaian layanan dengan iklan yang dijanjikan.

Berikutnya, satisfaction memiliki pengaruh yang signifikan terhadap trust (H5). Hal ini sesuai dengan studi terdahulu yang dilakukan oleh Javed \& Min (2019) yang menyatakan bahwa kepuasan dapat meningkatkan kepercayaan konsumen di industri belanja online. Berdasarkan hasil SEM, indikator satisfaction yang berkontribusi paling kuat adalah puas dengan pengalaman belanja di e-commerce. Responden merasa puas dengan pengalaman belanja di situs e-commerce. Oleh karena itu, pelaku industri e-commerce dapat meningkatkan serta memberikan variasi agar konsumen memiliki pengalaman belanja yang menyenangkan. Moriuchi \& Takahashi (2016) menyatakan bahwa kepuasan terhadap pengalaman belanja di situs e-commerce dapat meningkatkan kepercayaan konsumen. Peningkatan kepuasan konsumen e-commerce akan berdampak pada peningkatan kepercayaan konsumen.

Selanjutnya, brand image tidak memiliki pengaruh yang signifikan terhadap loyalitas (H6). Hasil ini berbeda dengan penelitian terdahulu yang dilakukan oleh Alic et al. (2020) yang mengungkapkan bahwa secara simultan brand image mampu memengaruhi loyalitas konsumen. Hal ini mengindikasikan bahwa ketika perusahan e-commerce memiliki brand image yang baik, maka hal ini belum tentu dapat meningkatkan loyalitas konsumen secara signifikan.

Selanjutnya, satisfaction memiliki pengaruh yang signifikan terhadap loyalty (H7). Hasil tersebut sejalan dengan penelitian terdahulu yang dilakukan oleh Aldweeri et al. (2018) yang mengungkapkan bahwa kepuasan konsumen mampu meningkatkan loyalitas. Berdasarkan hasil SEM, indikator satisfaction yang berkontribusi paling kuat adalah puas dengan pengalaman belanja di situs e-commerce. Safa \& Von (2016) mengungkapkan bahwa kepuasan merupakan faktor utama dalam pembentukan loyalitas. Pelanggan 
yang puas berpeluang untuk melakukan pembelian kembali sehingga memberikan keuntungan jangka panjang bagi perusahaan. Peningkatan pengalaman belanja yang dirasakan oleh konsumen menjadi indikator penting yang dilakukan oleh perusahaan untuk meningkatkan kepuasan dan loyalitas.

Berikutnya, trust memiliki pengaruh yang signifikan terhadap loyalitas (H8). Hasil ini sejalan dengan penelitian terdahulu yang dilakukan oleh Boonlertvanich (2019) yang mengungkapkan bahwa kepercayaan secara simultan dapat meningkatkan loyalitas. Berdasarkan hasil SEM, indikator trust yang berkontribusi paling kuat adalah keandalan situs e-commerce. Keandalan layanan ini dapat meningkatkan kepercayaan konsumen yang berdampak pada loyalitas. Mustafa (2011) mengungkapkan bahwa kepercayaan dipandang sebagai salah satu anteseden paling relevan dalam hubungan yang stabil dan kolaboratif. Salah satu indikator penting untuk membentuk kepercayaan konsumen e-commerce adalah dengan memberikan layanan yang dapat diandalkan. Keandalan layanan ini dapat meningkatkan kepercayaan konsumen yang berdampak pada loyalitas.

Selain pengaruh langsung, penelitian ini juga memiliki pengaruh tidak langsung. Pada penelitian ini, tingkat signifikansi pada Tabel 6 dengan thitung harus bernilai > 1,96.

Tabel 6. Pengaruh tidak langsung antar variabel

\begin{tabular}{|c|c|c|c|c|c|c|}
\hline \multicolumn{4}{|c|}{ Pengaruh tidak langsung antar variabel } & Koefisien jalur & t-hitung & Simpulan \\
\hline $\begin{array}{l}\text { Social } \\
\text { marketing }\end{array}$ & media $\rightarrow$ Brand image & $\rightarrow$ & Loyalty & 0.11 & 1.53 & Tidak signifikan \\
\hline $\begin{array}{l}\text { Social } \\
\text { marketing }\end{array}$ & media $\rightarrow$ Satisfaction & $\rightarrow$ & Loyalty & 0.07 & 1.47 & Tidak signifikan \\
\hline $\begin{array}{l}\text { Social } \\
\text { marketing }\end{array}$ & media $\rightarrow$ Trust & $\rightarrow$ & Loyalty & 0.19 & 3.68 & Signifikan \\
\hline
\end{tabular}

Besar pengaruh tidak langsung dari social media marketing terhadap loyalitas melalui brand image adalah 0.20 dengan nilai t-hitung sebesar 2.73. Hal ini menunjukkan bahwa hubungan tersebut signifikan karena nilai t-hitung diatas 1.98. Berdasarkan temuan tersebut, dapat disimpulkan bahwa pengaruh signifikan akan terjadi jika industri e-commerce melakukan kegiatan social media marketing untuk meningkatkan brand image, sehingga berdampak pada peningkatan loyalitas konsumen. Hasil ini berbeda dengan penelitian yang dilakukan oleh Bilgin (2018) yang menyatakan bahwa brand image dapat memediasi keberadaan variabel social media marketing terhadap loyalty.

Selanjutnya besar pengaruh tidak langsung dari social media marketing terhadap loyalitas melalui satisfaction adalah 0.07 dengan nilai t-hitung sebesar 1.47. Hal ini menunjukkan bahwa hubungan tersebut tidak signifikan karena nilai t-hitung kecil dari 1.98. Berdasarkan temuan tersebut, dapat disimpulkan bahwa tidak terjadi pengaruh signifikan antara social media marketing dengan loyalitas melalui satisfaction. Hasil ini berbeda dengan penelitian yang dilakukan oleh Yadav \& Rahman (2018) yang menyatakan bahwa satisfaction dapat memediasi keberadaan variabel social media marketing terhadap loyalty.

Besar pengaruh tidak langsung dari social media marketing terhadap loyalitas melalui trust adalah 0.08 dengan nilai t-hitung sebesar 3.68. Hal ini menunjukkan bahwa hubungan tersebut signifikan karena nilai t-hitung diatas 1.98. Berdasarkan temuan tersebut, dapat disimpulkan bahwa pengaruh signifikan akan terjadi jika industri e-commerce melakukan kegiatan social media marketing untuk meningkatkan kepercayaan konsumen, sehingga berdampak pada peningkatan loyalitas. Dimensi personalization mempunyai nilai terbesar dalam membentuk social media marketing dengan kontribusi indikator terbesar adalah memasang konten yang dapat menarik minat konsumen di media sosial instagram. Temuan tersebut didukung oleh penelitian Ibrahim \& Aljarah (2018) mengungkapkan bahwa kepercayaan konsumen dapat memediasi keberadaan variabel social media marketing terhadap loyalitas konsumen. Jakic et al. (2017) mengungkapkan bahwa perusahaan yang aktif melakukan kegiatan pemasaran melalui media sosial akan dapat meningkatkan kepercayaan konsumen. 


\section{KESIMPULAN}

Penelitian ini menganalisis pengaruh social media marketing terhadap brand image, satisfaction, trust terkait dengan loyalitas pelanggan e-commerce. Dalam penelitian ini terdapat delapan hipotesis, dimana dua diantaranya tidak signifikan. Hipotesis yang diterima adalah; social media marketing memiliki pengaruh signifikan terhadap brand image $(\mathrm{H} 1)$, social media marketing memiliki pengaruh signifikan terhadap trust $(\mathrm{H} 3)$, brand image memiliki pengaruh signifikan terhadap satisfaction (H4), satisfaction memiliki pengaruh signifikan terhadap trust (H5), satisfaction memiliki pengaruh signifikan terhadap loyalitas (H7), dan trust memiliki pengaruh signifikan terhadap loyalitas (H8). Sedangkan hipotesis yang ditolak adalah; tidak terdapat pengaruh signifikan antara social media marketing dengan satisfaction (H2), dan tidak terdapat pengaruh signifikan antara brand image dengan loyalitas (H6). Lebih lanjut, penelitian ini memberikan wawasan tentang pentingnya loyalitas konsumen pada industri $e$-commerce.

\section{SARAN TEORITIS}

Penelitian ini mempunyai saran implikasi teoritis yang teruji secara empiris yaitu pengaruh social media marketing, brand image, satisfaction dan trust terhadap loyalitas konsumen e-commerce. Model dalam penelitian telah memenuhi syarat uji kelayakan goodness of fit sehingga dapat memberikan referensi pustaka terkait loyalitas konsumen e-commerce.

Penelitian ini hanya meneliti situs e-commerce $\mathrm{C} 2 \mathrm{C}$ (consumer-to-consumer), sehingga penelitian selanjutnya dapat melakukan penelitian pada kategori e-commerce lainnya seperti B2B (business-tobusiness), B2C (business-to-consumer), dan $\mathrm{C} 2 \mathrm{~B}$ (consumer-to-business). Penelitian selanjutnya dapat menggunakan platform media sosial lainnya seperti Facebook, Twitter, Youtube, dan Tiktok, serta dapat membandingkan/uji beda pengaruh antar media sosial terhadap relationship marketing dan loyalitas konsumen e-commerce. Selain itu, penelitian selanjutnya dapat mempertimbangkan variabel lainnya yang dapat berpengaruh pada loyalitas konsumen e-commerce, diantaranya e-service quality (Fajri \& Maruf, 2017), promotion (Yadav \& Rahman, 2017), dan value equity (Zaryab et al., 2019).

\section{SARAN PRAKTIS}

Hasil penelitian ini diharapkan dapat bermanfaat bagi pelaku industri e-commerce $\mathrm{C} 2 \mathrm{C}$ (consumer to consumer). Berdasarkan analisis jalur, social media marketing berpengaruh signifikan terhadap loyalitas melalui kepercayaan. Hal ini dapat menunjukkan bahwa social media marketing dapat meningkatkan kepercayaan konsumen dan berdampak pada loyalitas berbelanja di situs e-commerce. Dimensi personalization mempunyai nilai terbesar dalam membentuk social media marketing dengan kontribusi indikator terbesar adalah memasang konten yang dapat menarik minat konsumen di media sosial instagram. Oleh karena itu, pelaku industri e-commerce dapat memasang konten yang menarik dengan memberikan informasi yang bermanfaat, sehingga timbul keinginan konsumen untuk merekomendasikan kepada teman untuk mengunjungi akun instagram situs e-commerce. Konsumen yang tertarik atas informasi yang dipasang situs e-commerce di media sosial instagram akan membagikan informasi tersebut kepada teman dan kerabat. Hal ini secara tidak langsung dapat memperluas sebaran informasi serta dapat meningkatkan kepercayaan konsumen.

Kegiatan social media marketing mampu meningkatkan kepercayaan konsumen dan memberikan kontribusi terbesar terhadap loyalitas konsumen e-commerce. Pelaku industri e-commerce dapat meningkatkan kepercayaan konsumen dengan cara mempertahankan dan meningkatkan akurasi kesesuaian deskripsi produk dengan kondisi yang sebenarnya. Pelaku industri e-commerce harus memastikan bahwa penjual yang bekerja sama dengan pelaku industri memberikan keterangan produk yang sesuai dengan kondisi sebenarnya. Jika industri e-commerce mampu mempertahankan dan meningkatkan akurasi kesesuaian produk, maka hal ini akan dapat meningkatkan loyalitas konsumen. Konsumen yang loyal akan memberikan keuntungan bagi pelaku industri e-commerce dalam menjaga keberlangsungan di pasar belanja online. Hal ini dikarenakan kontribusi terbesar dalam membentuk loyalitas adalah konsumen akan melakukan pembelian kembali di situs e-commerce dan akan memilih situs $e$-commerce ketika berbelanja online. 


\section{REFERENSI}

Akbar, M., \& Pavej, N. (2009). Impact of service quality, trust, and consumer satisfaction on customer loyalty. ABAC Journal, 29(1), 24-38.

Aldweeri, R., Morena, A., \& Obeidat, Z. (2018). The Effect of e-service quality on Jordanian students eloyalty: an empirical study in online retailing. Industrial Management \& Data Systems, 119(4), 902923.

Alfian, N., \& Nilowardono, S. (2019). The influence of social media marketing instagram, word of mouth, and brand awareness of purchase decision on arthenis tour and travel. International Journal of Entrepreneurship and Business Development, 2(2), 218-226.

Alic, A., Cinjarevic, M., \& Agic, E. (2020). The role of brand image in consumer brand relationships: similarities and differences between national and private label brands. Management and Marketing Knowledge Society, 15(1), 1-16.

Amalina, A. (2016). Pengaruh social media marketing terhadap brand loyalty dengan brand trust sebagai variabel intervening. Jurnal Ilmu Manajemen, 4(3), 1-12.

Andreani, F., Taniaji, T., \& Puspitasari, R. (2012). The impact of brand image, customer loyalty with customer satisfaction as a mediator in McDonalds. Jurnal Manajemen dan Kewirausahaan, 14(1), 63-70.

Anizir, A., \& Wahyuni, R. (2017). Pengaruh social media marketing terhadap brand image perguruan tinggi swasta di Kota Serang. Seminar Nasional Riset Terapan, 3(2), 1-14.

APJII. (2019). Hasil Survei Penetrasi Dan Perilaku Pengguna Internet Indonesia [online] https://apjii.or.id/survei2018s/download/Nf64e7SOTawujD1ZEUiGQMYlk X xszV (accessed 10 Auguts 2020).

Baig, S., Rehman, M., Javed, E., Aslam, T., \& Shafique, A. (2015). Mediating roles of customer satisfaction and customer trust in building brand loyalty. Business Management Dynamics, 4(10), 1-29.

Ball, D., Simoes, C., \& Machas, A. (2004). The role of communication and trust in explaining customer loyalty. European Journal of Marketing, 38(9), 1272-1293.

Bilgin, Y. (2018). The effect of social media marketing activities on brand awareness, brand image, and brand loyalty. Business and Management Studies, 6(1), 128-148.

Boonlertvanich, K. (2019). Service quality, satisfaction, trust, and loyalty: The moderating role of mainbank and wealth status. International Journal of Bank Marketing, 37(1), 278-302.

Cheung, M.L., Pires, G., Rosenberg, P., \& Leung, W. (2020). Investigating the role of social media marketing on value co-creation and engagement: an empirical study in China and Hongkong. Australian Marketing Journal, 1(1), 1-13.

Duffett, R. (2017). Influence of social media marketing communications on young consumers attitudes', Young Consumers, 18(1), 19-39.

Fajri, D., \& Maruf, J. (2018). Pengaruh social media marketing dan promosi harga terhadap kepuasan konsumen di maskapai penerbangan Airasia Banda Aceh. Jurnal Ilmiah Mahasiswa Ekonomi Manajemen, 3(3), 33-48.

Gautam, V., \& Sharma, V. (2017). The mediating role of consumer relationship on the social media marketing and purchase intention relationship with special references to luxury fashion brands. Journal of Promotion Management, 2(1), 1-17. 
Ghozali, I., \& Latan, H. (2015). Partial Least Squares: Konsep, Teknik, dan Aplikasi Menggunakan SmartPLS 3.0 Untuk Penelitian Empiris. BPUP Publications. Indonesia.

Hair, R., Black, W., Babin, B., Anderson, R., \& Tarham, R. (2006). Multivariate Data Analysis (5th ed). Pearson. New Jersey.

Haryono, S. (2016). Metode SEM Untuk Penelitian Manajemen dengan Amos Lisrel PLS. Intermedia Utama. Indonesia.

Hermanda, A., Sumarwan, U., \& Tinaprilla, N. (2019). The effect of social media influencer on brand image, self-concept, and purchase intention. Journal of Consumer Science, 4(2), 76-89.

Hoang, D. (2015). The impact of relationship marketing on customer loyalty in the airline industry. Centria University of Applied Sciences, 2(1), 1-15.

Hsieh, M., Pan, S., \& Setiono, R. (2004). Product, corporate, and country-image dimensions and purchase behavior: a multicountry analysis. Journal of the Academy of Marketing Science, 32(3), 251-70.

Ibrahim, B., \& Aljarah, A. (2018). Dataset of relationships among social media marketing activities, brand loyalty, revisit intention. Journal Data in Brief, 21(1), 1823-1828.

Ismail, A. (2017). The influence of perceived social media marketing activities on brand loyalty the mediation effect of brand and value consciousness. Asia Pacific Journal of Marketing and Logistics, 29(1), 129-144.

Iversen, N., \& Hem, L. (2008). Provenance association as core value of place umbrella brands: A framework of characteristics. European Journal of Marketing, 42(4), 603-626.

Jakic, A., Wagner, M., \& Meyer, A. (2017). The impact of language style accommodation during social media interactions on brand trust. Journal of Service Management, 28(3), 418-441.

Jalilvand, M., Nasrolahi, V., \& Kazemi M, Khazaei P. (2017). Social responsibility influence on customer trust in hotels: mediating effects of reputation and word-of-mouth. Tourism Review, 72(1), 1-14.

Jamaev, M., Kumar, D., \& Hanaysha, J. (2012). Impact of relationship marketing on consumer loyalty in the Banking sector. Far East Journal of Pyschology and Business, 6(3), 36-55.

Javed, M., \& Min, W. (2019). Effects of online retailer after delivery services on repurchase intention: An empirical analysis of customers past experience and future confidence with the retailer. Journal of Retailing and Consumer Services, 54(1), 1-7.

Khan, I., Dongping, H., \& Wahab, A. (2016). Does culture matter in effectiveness of social media marketing strategy: An investigation of brand fan pages. Aslib Journal of Information Management, 68(6), 694715.

Kotler, P., \& Keller, K. (2016). Marketing Management. Pearson. New Jersey.

Lee, H., Lee, C., \& Wu, C. (2011). Brand image strategy affects brand equity after M\&A. European Journal of Marketing, 45(7), 109-111.

Liao, T. and Keng. (2013). Online shopping delivery delay: finding a psychological recovery strategy by online consumer experiences. Computers in Human Behavior, 29(4), 1849-1861.

Lu, H., \& Hsiao, K. (2010). The influence of extro/introversion on the intention to pay for social networking sites. Information and Management, 47(3), 150-157.

Morgan, R., \& Hunt, S. (1994). The commitment-trust theory of relationship marketing. Journal of Marketing, 58(3), 20-38. 
Moriuchi, E., \& Takahashi, I. (2016). Satisfaction trust and loyalty of repeat online consumer within the Japanese online supermarket trade. Australian Marketing Journal, 24(2), 146-156.

Mothersbaugh, D., \& Hawkins, D. (2016). Consumer Behavior Building Marketing Strategy. McGraw-Hill. New York.

Mustafa, E. (2011). Determinants of e-commerce customer satisfaction, trust, and loyalty in Saudi Arabia. Journal of E-Commerce Research, 12(1), 78-93.

Ngo, V., \& Pavelkova, D. (2017). Moderating and mediating effects of switching costs on the relationship between service value, customer satisfaction, and customer loyalty. Journal of International Studies, 10(1), 9-33.

Olivier, R. (1999). Whence consumer loyalty. Journal of Marketing, 63(1), 33-44.

Pavlou, P., \& Fygenson, M. (2006). Understanding and predicting electronic commerce adoption: an extension of the theory of planned behavior. MIS Quarterly, 30(1), 115-143.

Peelen, E. (2005). Customer Relationship Management. Prentice Hall. New York.

Poturak, M. \& Softic, S. 2019. Influence of Social Media Content on Consumer Purchase Intention: Mediation Effect of Brand Equity. Eurasian Journal of Business and Economics. 12(23): 17- 43.

Pratama, D. (2016). Pengaruh social media marketing dan kepuasan pelanggan terhadap loyalitas merek. Jurnal Ilmiah Fakultas Ekonomi dan Bisnis, 5(1), 1-11.

Riezebos, R. (2003). Brand Management: A Theoretical and Practical Approach. Pearson. London.

Rugova, B., \& Prenaj, B. (2016). Social media as marketing tools for SME: Opportunities and challenges. Academic Journal of Business: Administration, Laws, and Social Science, 2(3), 85-97.

Saeed, R., Lodhi, R., Mehmood, A., \& Ishfaque, U. (2013). Effect of brand image on brand loyalty and role of customer satisfaction in it. World Applied Science Journal, 26(10), 1364-1370.

Safa, N., \& Von, R. (2016). Customers repurchase intention information in e-commerce. South Africa Journal of Information Management, 18(1), 1-9.

Santos, J. (2003). E-service quality: a model of virtual service quality dimensions. Managing Service Quality, 13(3), 233-246.

Sekaran, U., \& Bougie, R. (2013). Research Methods for Business. John Wiley. London.

Seo, E., \& Park, J. (2018). A study on the effects of social media marketing activities on brand equity and custome response in the airline industry. Journal of Air Transport Management, 66(18), 36-41.

Severi, E., \& Ling, C. (2013). The mediating effects of brand association, brand loyalty, brand image and perceived quality on brand equity. Asian Social Science, 9(3), 1-15.

Simon, K. (2019). Global Digital Overview [online] https://wearesocial.com/blog/2020/01/digital-2020-38-billion-people-use-social-media (accessed 20 August 2020).

Singh, J., \& Sirdeshmukh, D. (2000). Agency and trust mechanisms in consumer satisfaction and loyalty judgments. Journal of the Academy of Marketing Science, 28(1), 150-167.

Statista. (2020). Number of Internet Users in Indonesia From 2017 - 2023 [online] https://www.statista.com/statistics/254456/number-of-internet-users-in-indonesia/ (accessed 15 May 2020).

Subaesbasni, S., Risnawaty, H., \& Wicaksono, A. (2018). Effect of brand image, the quality and price on customer satisfaction and implications for customer loyalty. International Review of Management and Marketing, 9(1), 90-97. 
Sublibhavi, B., \& Shivashankar, K. (2017). The impact of brand image on customer loyalty towards private label brands: The mediating effect of satisfaction. International Journal of Marketing and Financial Management, 5(8), 43-50.

Sun, H. (2010). Transferring attribute of e-commerce systems into business benefits: a relationship perspective. Journal of E-Commerce Research, 11(2) 92-108.

Tatar, S. and Erdogmus, I. (2016). The effect of social media marketing on brand trust and brand loyalty for hotels. Information Technology Tourism, 16(1), 249-263.

Tuten, T. (2008). Advertising 2.0: Social Media Marketing In a Web 2.0 World. Greenwood. California.

Upamanyu, N., \& Mathur, G. (2012). Effect of brand trust, brand affect, and brand image on customer brand loyalty and consumer brand extension attitude in FMCG sector. Practice and Research in Marketing, 3(2), 1-15.

Wang, T., Yeh, R., \& Yen D. (2015). Influence of customer identification on online usage and purchasing behaviors in social commerce. International Journal of Human Computer Interaction, 31(4), 805814.

Wijayanto S.H. (2008). Structural Equation Modeling Dengan LISREL 8.8. Graha Ilmu. Yogyakarta. Indonesia.

Yadav, M., \& Rahman Z. (2017). Measuring consumer perception of social media marketing activities in e-commerce industry. Telematics and Informatics, 34(7), 1294-1307.

Zahay, R. (2015). Internet Marketing Intregrating Online \& Offline Strategies. Cengage. Boston.

Zaryab, S., Yezheng, L., Tahir, I., \& Hameed, Z. (2019). Impact of social commerce constructs and social support on social commerce intentions. Information Technology. 32(1), 68-93.

Zhang, K., Benyoucef, M., \& Zhao S. (2016). Building brand loyalty in social commerce: The case of brand microblogs Electronic Commerce Research and Applications, 15(1), 14-25. 